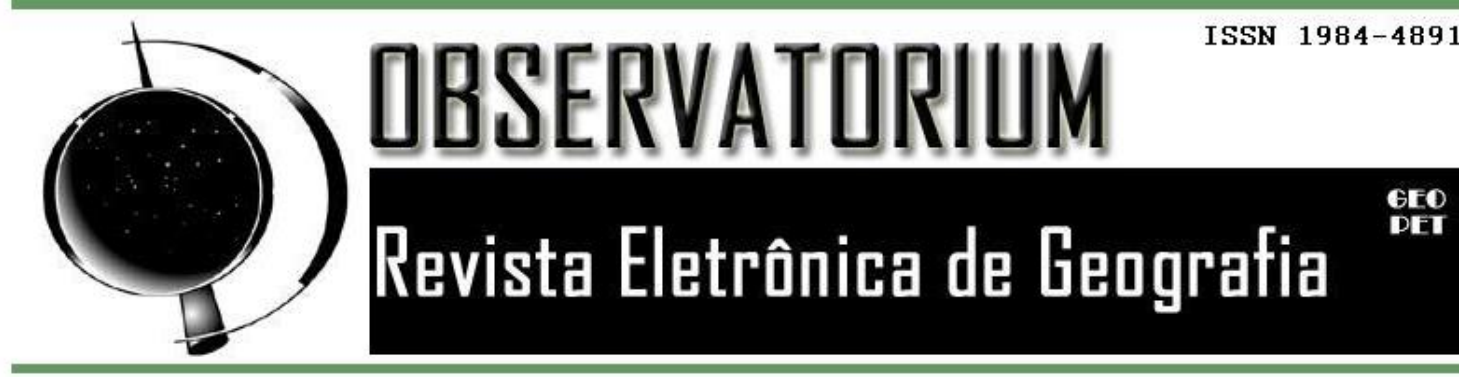

\title{
Humboldt anticolonial
}

Humboldt anticolonial

\section{Tulio Barbosa}

Docente do Instituto de Geografia da Universidade Federal de Uberlândia. Doutor em Geografia (UNESP) e Doutor em História (UFU).

E-mail: tuliobarbosa@ufu.br

Em Homenagem aos 250 Anos de Alexander von Humboldt.

\section{Resumo:}

O presente trabalho é resultado da participação em evento organizado pelo PET MEC Geografia da Universidade Federal de Uberlândia e convidado para transcrever a fala que ocorreu no seminário "Clássicos da Geografia", tal evento foi organizado pelo PET MEC Geografia tendo como tutor o professor Dr. Mirlei Fachini Vicente Pereira. Neste sentido, partimos da compreensão de Humboldt como um cientista que enxergava na pesquisa a própria ação quando essa consorciada com a libertação de tudo que possam causar sofrimento $\mathrm{O}$ fascínio com a obra de Humboldt na Geografia brasileira é resultado de uma postura acadêmica distante da sociedade. A obra de Humboldt é o resultado de uma postura radical contra a opressão, o racismo e a violência europeia empreendida aos povos oprimidos em todos os espaços colonizados; assim, esses fundamentos anticolonialistas em Humboldt precisam de ecos na própria Geografia brasileira. $\mathrm{O}$ anticolonialismo de Humboldt nos força a pensar uma ciência geográfica comprometida com a práxis transformadora da realidade por meio da destruição de toda forma de opressão.

Palavras-Chave: Antirracismo. Anticolonialismo. Anti-imperialismo. Geografia Anticolonial.

\begin{abstract}
:
This work is the result of participation in an event organized by PET MEC Geography at the Federal University of Uberlândia and invited to transcribe the speech that took place in the seminar "Classics of Geography". This event was organized by PET MEC Geography with Dr. Mirlei Fachini Vicente Pereira. In this sense, we start from the understanding of Humboldt as a scientist who saw in his research his own action when this consortium with the liberation of everything that could cause suffering. The fascination for Humboldt's work in Brazilian
\end{abstract}




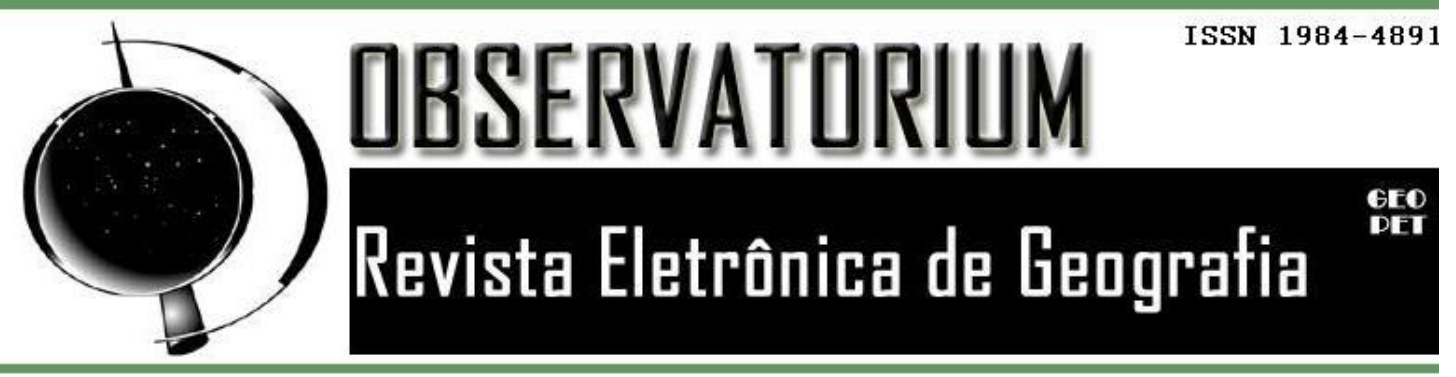

Geography is the result of an academic position away from society. Humboldt's work is the result of a radical stance against oppression, racism and European violence against oppressed peoples in all colonized spaces; therefore, these anticolonial positions in Humboldt need echoes in Brazilian geography itself. Humboldt's anti-colonialism forces us to think of a geographical science committed to the reality-transforming praxis through the destruction of all forms of oppression.

Keywords: Anti-racism. Anticolonialism. Anti-imperialism. Anticolonial Geography.

\section{Introdução}

“O povo aprende por meio da participação e da observação”.

Fred Hampton, presidente do Partido dos Panteras Negras em Illinois, discurso realizado na Igreja de Olivet em 1969.

Humboldt foi anticolonial, mas também foi inimigo de Karl Marx e estimulou o exílio do pensador revolucionário comunista. Também Humboldt criticou a capacidade de liderança e de revolução de Simon Bolivar e Karl Marx ofendeu Simon Bolivar de forma preconceituosa. Humboldt admirava a democracia e o presidencialismo dos Estados Unidos, mas o fim da escravidão nessa democracia ocorreu apenas em 1863. Humboldt tem as contradições do seu tempo e leva em sua formação de humanidade o espírito aristocrático e burguês da Alemanha. Essas contradições Marx e Engels apresentam de forma ímpar na Ideologia Alemã e com isso conseguimos compreender os processos de alienação, estranhamento e distanciamento de questões tão caras e precisas para efetivarmos melhorias significativas no mundo; assim, os autores do Manifesto Comunista também estão inseridos nas suas próprias críticas.

Humboldt é um oposicionista contra toda uma tradição preconceituosa europeia que tem pensadores importantes e influentes nessa construção ideológica, dentre tais o próprio Hegel. Também criticou o racismo do 


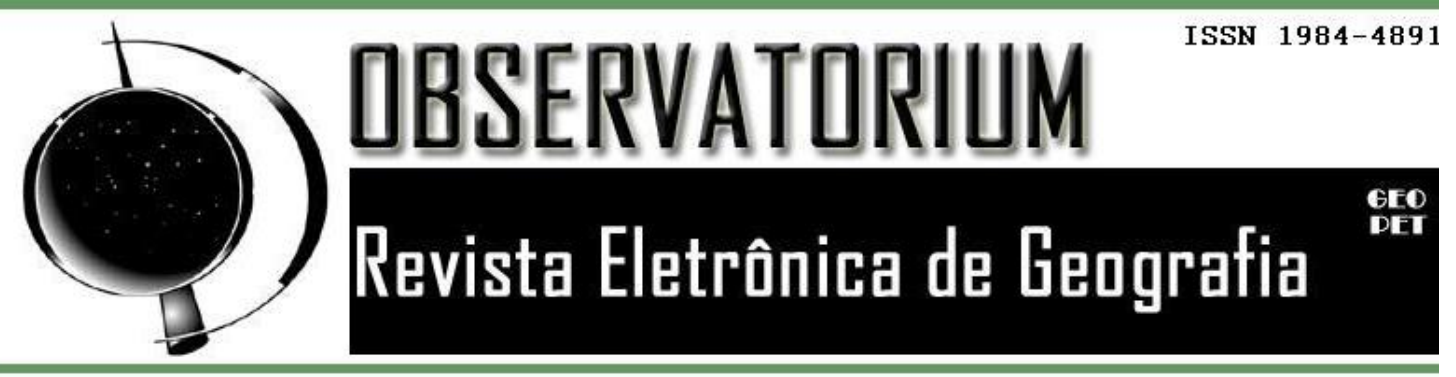

conde de Buffon e denuncia sua ciência como irreal e até mesmo conspiratória para a promoção da ignorância. Humboldt já combatia as "fake news".

Assim, não podemos acusar Humboldt de compactuar com os valores burgueses simplesmente, pois o cientista procurou compreender e denunciar um mundo que não fosse capaz de expressar a plena liberdade. Tal como Marx também denuncia Simon Bolivar por tecer no sulamericano qualidades burguesas que não estariam compatíveis com a moral branca europeia colonizadora. O julgamento de Humboldt deve ser feito pela questão ética e nunca pela moralidade, pois esse cientista denunciou o racismo, a escravidão e o preconceito, ao mesmo tempo em que elencou a natureza como uma condição permanente de nossa humanidade.

Na minha tese de doutorado em Geografia (Estética romântica germânica e a paisagem em Humboldt: percurso da geografia, sob a orientação do professor Dr. João Osvaldo Rodrigues Nunes defendida no ano de 2011) provei que Humboldt era originário de toda uma construção científica herdada de um racionalismo que foi pouco a pouco substituído por um sentido humanístico oriundo do romantismo germânico. O que não compreendia na época é que essa tese para ser completa precisava de um respaldo social do tempo presente, de um instrumento de luta e transformação, ou seja, indiquei como essa transformação partiu de uma condição romântica e de um sujeito que buscou na ciência validar a construção de outro mundo, mas me ausentei em ver os problemas reais do nosso cotidiano a partir da leitura de um europeu anticolonial, de um europeu que traiu o colonialismo espanhol para denunciar todas as mazelas do mundo, todos os problemas causados pelos humanos ditos "civilizados". Também nessa minha tese trouxe questões sobre a relação da ciência a partir de Heidegger na composição da interpretação de Humboldt e não denunciei o nazismo desse filósofo o que venho realizar agora publicamente. Não se pode perdoar Heidegger.

Desde a escrita da tese já se passaram quase dez anos e o tempo somado ao compromisso anticolonial, anti-imperialista e antirracista me fizeram compreender que uma tese nunca está completa quando a mesma parte de uma necessidade em superar a opressão. As últimas leituras que realizei da obra de Humboldt me obrigaram a reavaliar minha construção científica quanto àquele 


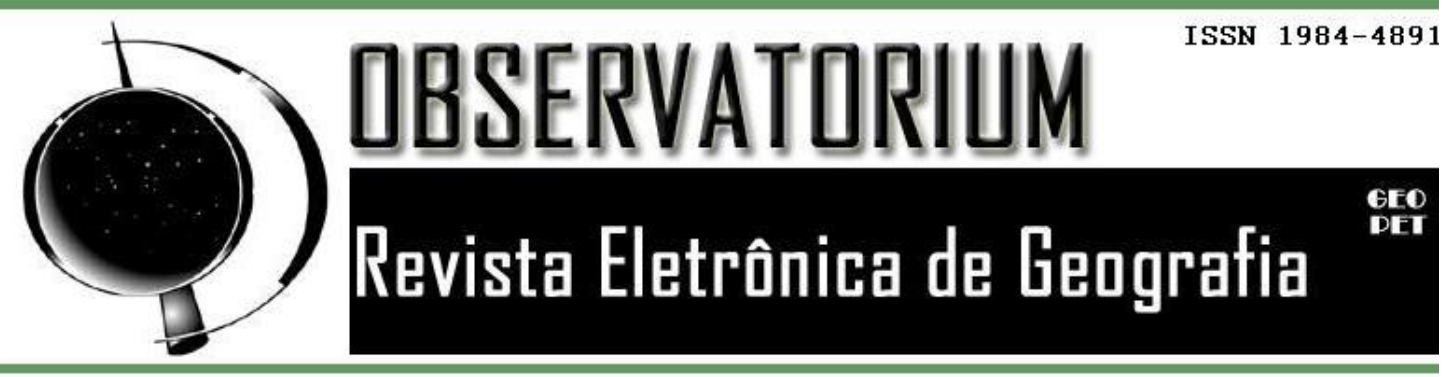

que promoveu uma revolução em todo mundo e lutou sem temor contra as forças da opressão; assim, me obriguei a forçar uma condição de reorganização de minha tese para pensar uma ação revolucionária a partir dos escritos de Humboldt e sua atuação numa ciência que compreende o espaço para além da manutenção do status quo, pois a cosmologia de Humboldt não foi centrada no modo de produção capitalista e sim na superação das relações de opressão pela subtração da dicotomia sociedade-natureza e, principalmente, pela construção de uma relação não exploratória fundando com isso uma sociedade equilibrada em todos os aspectos.

\section{Humboldt e a construção da liberdade}

Na verdade, a única coisa que pôde colher naquelas confidências pedregosas foi o insistente martelar da palavra equinócio equinócio equinócio, e o nome de Alexandre Von Humboldt. Gabriel García Márquez - Cem anos de solidão

É notório o conhecimento de parte considerável dos estudiosos da Geografia quanto a importância de Humboldt para essa ciência, mas ainda é insuficiente uma leitura que prime pelo discurso da transformação imediata da realidade suprimindo a pobreza, a opressão e a violência contra a classe trabalhadora.

Nós geógrafos e geógrafas brasileiras não podemos nos furtar aos penduricalhos dos conceitos e categorias, pois é preciso ter uma leitura transformadora da realidade, pois agora nesse momento há fome, miséria, opressão, violência e o terror contra os mais pobres. Não posso ler Humboldt na palidez de uma tese que não buscou diretamente a superação desse cenário; assim, o romantismo de Humboldt é preciso ser transformado em ação, já que nossa sociedade é marcada desde a colonização portuguesa por espoliação, violência e destruição.

Deste modo, o colonialismo, desde o seu nascimento, mostrou-se condutor das direções políticas, econômicas, sociais, culturais e tecnológicas, com 


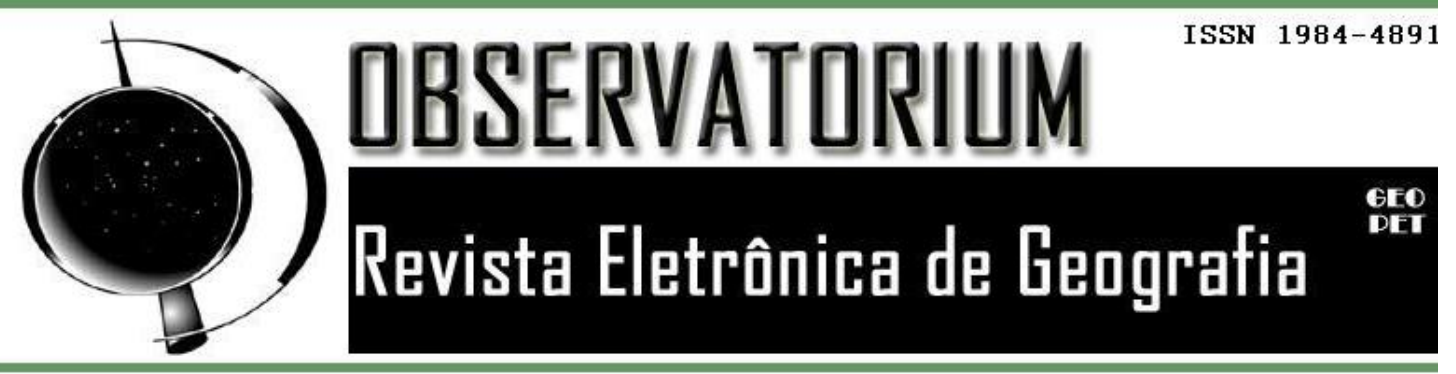

isso, empreendeu sobre a natureza uma força para a destruição da mesma objetivando o lucro e ao mesmo tempo a opressão para a consolidação desse modelo de exploração sobre a sociedade composta pelos povos indígenas e africanos (homens e mulheres livres que foram escravizados/escravizadas). O resultado desse processo foi a "naturalização" das consequências trágicas do capitalismo. Até mesmo geógrafo anticolonial como Lacoste (1965) “topou” essa "naturalização" ao enumerar as causas do subdesenvolvimento e não apresentar um plano ou mesmo uma ação contra a opressão capitalista.

Humboldt (1826) nas suas viagens feitas no continente americano colonizado pelos espanhóis teceu inúmeras críticas a escravidão e as condições de vida desses seres humanos que foram escravizados em nome da produção econômica e da concentração de renda. Assim, Humboldt (1826, p. 183) denunciou ao mesmo tempo a religião cristã como promotora da escravidão e os europeus como escravocratas: "La religion cristiana que favoreció en su origen tan poderosamente la libertad de los hombres, sirvió de pretexto á la codicia de los Europeos”.

Diante disso, Humboldt nos obriga a refletir a construção da liberdade pela negação de toda forma de servidão e nos coloca frente a frente com nossa situação atual na qual a religião cristã (algumas denominações religiosas e parte da Igreja Católica) tornou-se uma mola propulsora de ideias fascistas com argumentos "sólidos" para justificar a ganância e a cobiça de todos aqueles que tem fé no capitalismo e na sua opressão. A leitura de Humboldt nos coloca reconstruindo os processos históricos diante de nossa realidade espacial com todas as suas formulações econômicas, políticas, sociais, culturais e tecnológicas e suas consequências específicas para a classe trabalhadora. Tal como Humboldt também nos coloca em alerta quanto as diferenças na relação sociedade e natureza a partir do lócus social e econômico que nos encontramos, isto é, a beleza e a prudência da natureza são para poucos, enquanto a desgraça e as tragédias repercutem sempre para os mais pobres. Nem a natureza é igual.

Humboldt (1874) no segundo tomo do Cosmos na parte VI constrói uma narrativa histórica materialista e dialética ao apontar a ampliação do conhecimento científico e sua relação direta com o domínio da natureza 


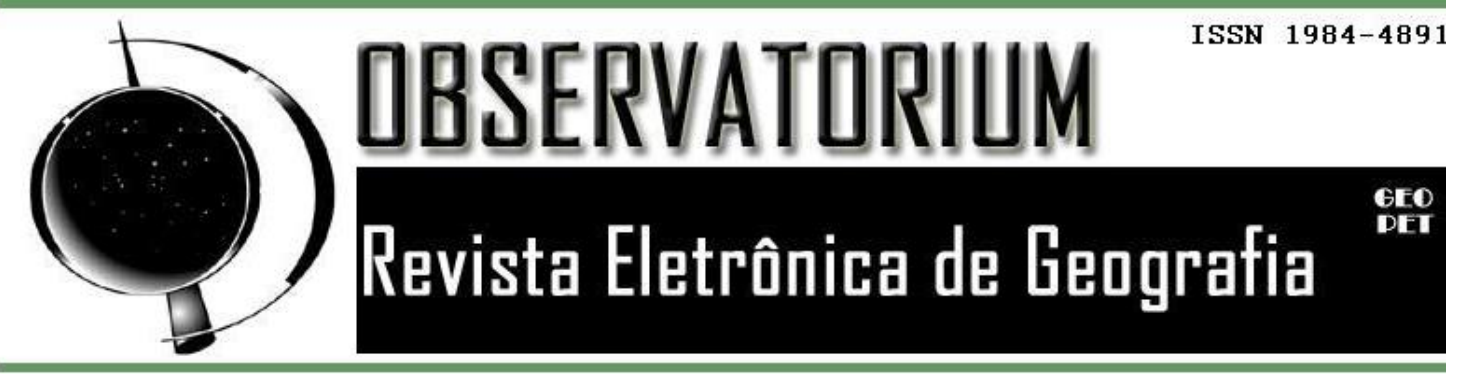

Diante disso, entendemos que Humboldt (1874) compreende a humanidade como a manifestação de uma existência que se organiza na relação dialética com a natureza e essa move-se como eterna e incorruptível nas suas bases biológicas, físicas e químicas. A natureza e a humanidade, desde que surgiu a segunda, são inseparáveis e indissolúveis na formulação de soluções para todos os problemas. O anticolonialismo de Humboldt está na superação da dicotomia como condição de vida, como forma e conteúdo ao mesmo tempo na relação da própria existência do Planeta Terra, isto é, promove o sentido da existência na realidade do ser a partir da vida diária com suas articulações de limites, extensões, intensidades e projeções.

Não podemos ler Humboldt sem vivenciar suas agendas e propostas para a humanidade que se deslocam pelo mundo a partir de uma cumplicidade de fatos que não podem ser assemelhados a nada até então, configurou todo um processo de edificação e de libertação pelas ciências, mas não uma ciência estruturada em cânones, sim uma ciência feita pela forja diária das necessidades de reflexão e intervenção na realidade buscando a supressão das questões que oprimem. A cosmologia de Humboldt continuou a ser formada enquanto ele continuou a refletir diretamente sobre o mundo, em outras palavras, Humboldt não promove uma ciência por meio de categorias engessadas e constituídas hierarquicamente, pois a ciência de Humboldt é a ciência de um projeto de humanidade que não pode ser furtada da natureza.

Humboldt não busca categorias operacionais de análise da realidade como moldura da realidade, ao contrário, salienta a realidade e seus movimentos para direcionar as urgências. A paisagem não é uma categoria utilizada por Humboldt, mas ela é um componente de suas análises, isso implica em considerar a paisagem como um elo entre o espírito científico e a urgência da realidade: o visto, o pensado e a ação. A paisagem de humanos escravizados trouxe questões de observações imediatas - aquelas que ocorrem no momento do olhar - para uma paisagem da indignação e do conflito - aquela paisagem que é processada pela ética. Deste modo, a paisagem não é a moldura é o próprio processo daquilo que está para aquilo deveria ser. 


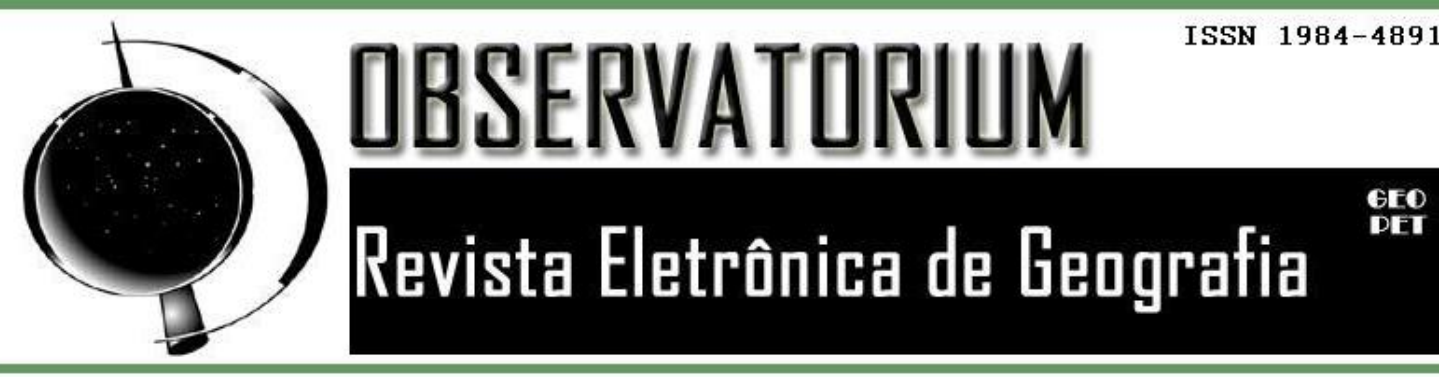

verificaram que um processo de melhor adequação das relações poderia dar mais lucros, como a possibilidade de homens e mulheres escravizadas terem suas famílias e suas cabanas. Sublinhamos que essa humanização é uma farsa produtiva e não o sentido real de uma humanidade com dignidade. Esses fazendeiros procuraram inovar para produzirem melhor. Humboldt apoiou essa inovação e ficou indignado com aqueles fazendeiros que não aderiram as novas formas de exploração, pois poderia modernizar o sentido da produção e consequentemente de todas as relações empreendidas em Cuba. Também o Estado não apoiou qualquer forma de mudança num primeiro momento, depois compreendeu que era necessário estabelecer novas relações de produção e subordinar os colonos a vontade da metrópole e garantir o melhor preço do açúcar.

Humboldt (2005, p. 233-234) estabelece a base da sua crítica a escravidão e ao colonialismo mostrando todos os malefícios sociais, políticos e estruturais da escravidão:

En todas partes donde se halla hace mucho tiempo establecida la esclavitud, el progreso sólo de la civilización influye mucho menos de lo que se quisiera en el trato que se da a los esclavos. La civilización de una nación rara vez se extiende a un gran número de individuos, y no llega a los que en los talleres están en contacto con los negros. Los propietarios, y yo los he conocido muy humanos, retroceden ante las dificultades que se presentan en los grandes plantíos; vacilan en alterar el orden establecido, en hacer innovaciones que no siendo simultáneas ni sostenidas por la legislación, o por la voluntad general, que sería un medio más poderoso, no conseguirían su objetivo, y quizás empeorarían la suerte de aquellos a quienes se quisiese aliviar. Estas consideraciones tímidas detienen el bien entre los hombres cuyas intenciones son las más benéficas y que se lamentan por haber recebido la triste herencia de instituciones bárbaras. Por conocer las circunstancias locales, saben que, para hacer un cambio esencial en la situación de los esclavos y conducirlos progresivamente al goce de la libertad, es menester una voluntad fuerte en las autoridades locales, el concurso de ciudadanos ricos e ilustrados, y un plan general en el cual se hallen calculadas todas las probabilidades de desorden y los medios de represión. Sin este concurso de acciones y de esfuerzos, la esclavitud se mantendrá con sus dolencias y sus excesos, como en la antigua Roma, al lado de la elegancia de costumbres, del progresso tan ponderado de los conocimientos, y de todos los prestigios de uma civilización acusada por la existencia de la esclavitud, y 


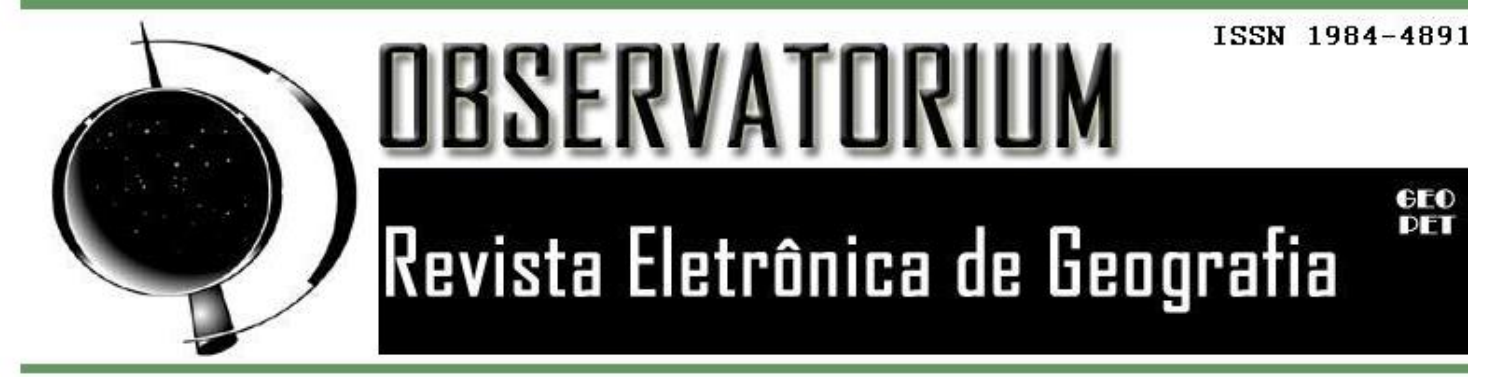

amenazada de ser tragada cuando llegue el tiempo de la venganza.

Interessante que Humboldt escreve o tempo todo sobre a urgência de uma transição pacífica do escravismo para o capitalismo, todavia essas palavras de paz e ordem sempre são sacudidas pela possibilidade da violência e essa oriunda do tempo de vingança. Essa vingança que Humboldt discretamente delineia na obra sobre Cuba é uma possibilidade para reorganizar a sociedade em outras bases. A vingança origina a revolução. Humboldt não nega o papel da paz pelas instituições do Estado por meio de reformas consideráveis, mas evidencia o zelo pela vingança daqueles que sofreram as mais terríveis condições de vida. A luta é feita para subtrair a opressão e todas as formas que violem a humanidade de homens e mulheres negras.

O tempo da vingança prossegue e o Estado espanhol atento consegue impedir que esses caminhos revolucionários sejam ampliados, já que a vingança é a violência usada como defesa por aqueles que são oprimidos. A atenção de Humboldt a luta anticolonial pelos tomou medidas radicais na centralidade da luta anti-escravista e com isso o apoio de nacionalistas anticolonialistas fizeram com que as elites locais continuassem elites.

Lo que el principio odioso del sistema colonial, una seguridad fundada en la enemistad de las castas, ha preparado desde hace siglos, estalla entonces con violencia. Por fortuna el número de negros era tan poco considerable en los nuevos estados del continente español, que a excepción de las crueldades ejecutadas en Venezuela, donde el partido realista había armado a los esclavos, no hubo venganzas de la población servil que ensangrentasen la lucha entre los independientes y los soldados de la metrópoli. Los hombres de color libres (negros, mulatos y mestizos) han abrazado con entusiasmo la causa nacional; y la raza cobriza ha permanecido en su desconfianza tímida y en su impasibilidad misteriosa, sin tomar parte en los movimientos de que ella, a pesar suyo, se aprovechará algún día. (HUMBOLDT, 2005, p. 223-224).

O domínio ideológico subtraiu a possibilidade de vingança, pois a Revolução empreendida por Bolivar não estimulou outras revoluções internas, já que o princípio da identidade nacional foi mais forte e agregou tantos trabalhadores livres negros e brancos, bem como escravizados. Mesmo assim, 


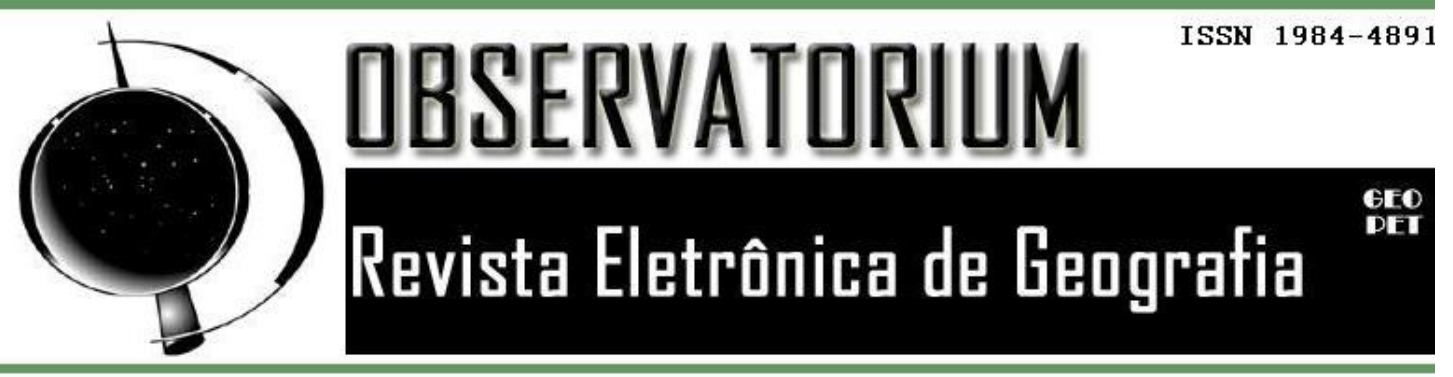

Humboldt naquele momento nutre uma esperança de que alguma forma esses escravizados e escravizas tomariam a situação por assalto e se moveriam de outras formas na organização de suas próprias vidas. Humboldt nunca escreveu um manifesto direto, mas propôs essa ação a partir de sua admiração pelo Estado democrático e pelo horror ao racismo e a escravidão.

Humboldt promove um olhar que odeia o racismo e se posiciona contra essa condição desumana. Nos dias de hoje, a partir da leitura desse legado de Humboldt também é importante nos posicionarmos de forma enfática contra todas as forças opressoras. Não podemos aceitar como natural a pobreza, a violência, o racismo, o machismo, a homofobia, o preconceito e o ódio estrutural contra a classe trabalhadora.

A raiz de todos os problemas e que existe muita dificuldade por parte dos geógrafos e geógrafas se posicionarem é o fim do capitalismo. Tal posicionamento deve ser entendido como a subtração desse modo de produção no qual a concentração de renda, de poder e de vida sempre trará a destruição e a opressão da classe trabalhadora.

Humboldt não apoia explicitamente a violência dos oprimidos contra os opressores, pois argumenta que uma sociedade violenta não poderá construir uma civilização adequada e progressista, mas também em vários momentos de sua obra incita questionamentos de maior dureza contra a opressão e questiona quem o lê para o posicionamento crítico contra a opressão e o apoio explícito aos oprimidos em suas respostas.

Correspondendo com Varnhagen em julho de 1837 Humboldt critica o posicionamento de Hegel e o coloca como uma pessoa que não consegue compreender o mundo além de suas próprias percepções, pois Hegel opina falsamente contra a América e sua população nativa e com isso demonstra preconceito e incapacidade reflexiva sobre a realidade. (HUMBOLDT, 1980).

A força política de Humboldt e de suas críticas a realidade que o mesmo viveu são ignoradas pelos pesquisadores e pesquisadoras brasileiras da Geografia, e eu me incluo entre essa ignorância, pois quando começamos a refletir a condição de nossa realidade e como observamos as paisagens de terror que é submetida a classe trabalhadora somos obrigados a nos posicionar feericamente 


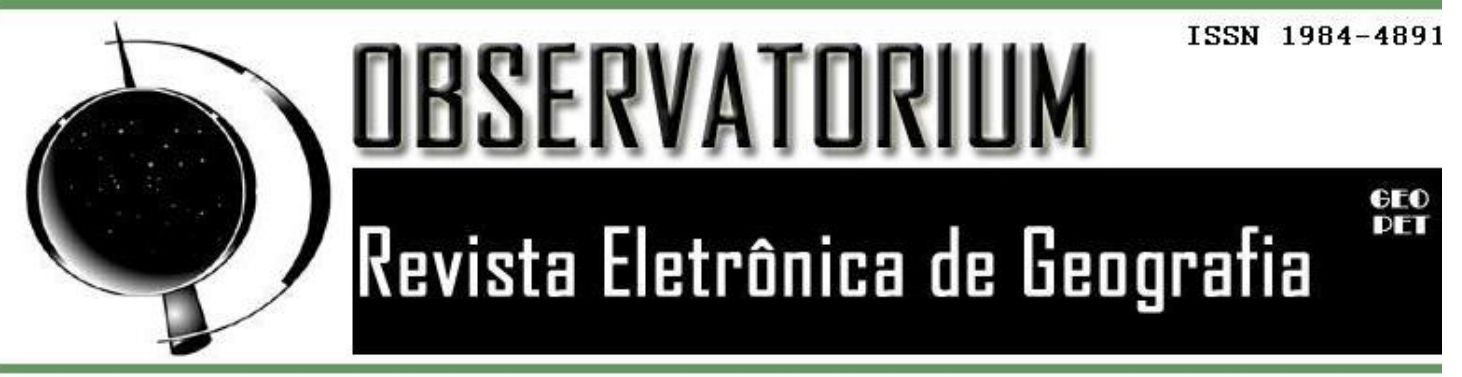

impacto considerável nos Estados Unidos, principalmente nos círculos mais progressistas e anti-escravistas.

A obra de Humboldt trouxe diretamente consequências positivas para o mundo e o sentido de justiça e de ética mostrou-se forte, todavia, essa condição de superação da opressão precisa ser ainda reforçada e coloca em prática de forma científica, democrática, anticolonialista e anticapitalista.

\section{Considerações finais}

A oportunidade de refletir as condições anticoloniais de Humboldt nos leva a reflexão de nossos próprios posicionamentos teóricos, metodológicos, didáticos e políticos. Humboldt sempre se colocou contra a colonização como um processo de empobrecimento contínuo dos povos nativos e dos escravizados, com isso evidenciou a colonização como uma definição anti-humana, como um processo de ruptura entre a humanidade e a ética, como se a natureza humana fosse lançada para longe.

Fred Hampton, presidente dos Panteras Negras, nos ensinou que a observação é algo fundamental para a compreensão do mundo. Humboldt anterior a Hampton já havia nos ensinado isso, bem como Hampton nos ensinou a olhar as paisagens da opressão e nos libertarmos o cientista Humboldt nos obriga a declararmos publicamente o que oprime a multidão de trabalhadores e trabalhadoras. Deste modo, constituirmos uma construção de uma nova sociedade.

Humboldt $(1970,160)$ denuncia a tragédia da colonização e busca esperança na fertilidade da vida, mas uma fertilidade guiada pelas mãos humanas, pelas mãos éticas e promotoras de um mundo melhor:

"Prouvera a Deus que, em todas as partes do Novo Continente, se tivessem conservado os nomes dos homens que, em vez de ensanguentarem o solo com as conquistas, depositaram nele as primeiras sementes dos cereais!”.

Somente conquistaremos as sementes dos cereais com a subtração da opressão física, econômica, política, social e material. Conquistaremos o pão, no sentido de Kropotkin (2011), desde que, conforme o autor, à revolução não falte 
